\title{
Computational Thermodynamics Aided Design of Novel Ferritic Alloys
}

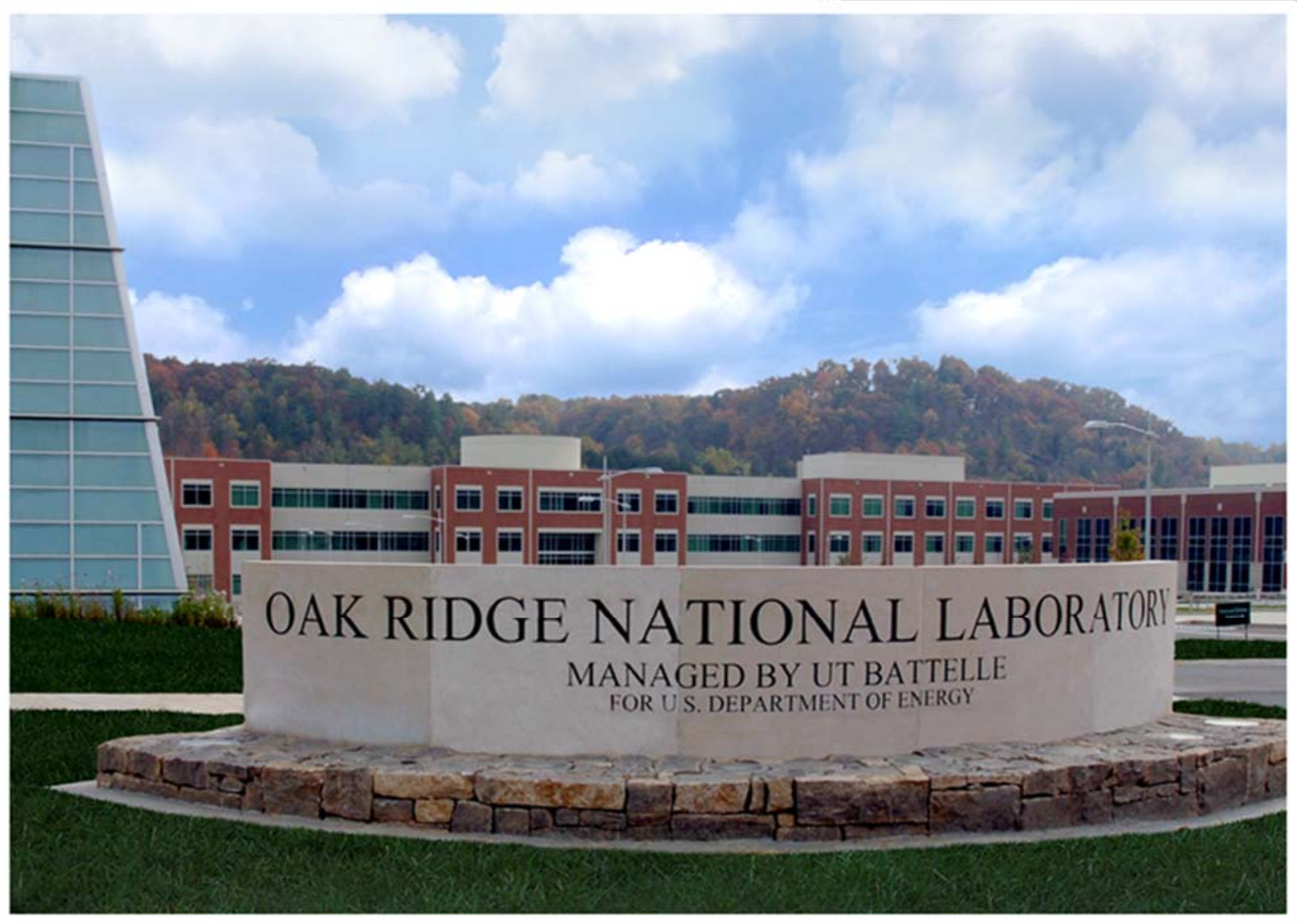

Approved for public release. Distribution is unlimited.
Ying Yang Tianyi Chen Lizhen Tan

June 30, 2016 


\section{DOCUMENT AVAILABILITY}

Reports produced after January 1, 1996, are generally available free via US Department of Energy (DOE) SciTech Connect.

Website http://www.osti.gov/scitech/

Reports produced before January 1, 1996, may be purchased by members of the public from the following source:

National Technical Information Service

5285 Port Royal Road

Springfield, VA 22161

Telephone 703-605-6000 (1-800-553-6847)

TDD 703-487-4639

Fax 703-605-6900

E-mail info@ntis.gov

Website http://www.ntis.gov/help/ordermethods.aspx

Reports are available to DOE employees, DOE contractors, Energy Technology Data Exchange representatives, and International Nuclear Information System representatives from the following source:

Office of Scientific and Technical Information

PO Box 62

Oak Ridge, TN 37831

Telephone 865-576-8401

Fax 865-576-5728

E-mail reports@osti.gov

Website http://www.osti.gov/contact.html

This report was prepared as an account of work sponsored by an agency of the United States Government. Neither the United States Government nor any agency thereof, nor any of their employees, makes any warranty, express or implied, or assumes any legal liability or responsibility for the accuracy, completeness, or usefulness of any information, apparatus, product, or process disclosed, or represents that its use would not infringe privately owned rights. Reference herein to any specific commercial product, process, or service by trade name, trademark, manufacturer, or otherwise, does not necessarily constitute or imply its endorsement, recommendation, or favoring by the United States Government or any agency thereof. The views and opinions of authors expressed herein do not necessarily state or reflect those of the United States Government or any agency thereof. 


\section{COMPUTATIONAL THERMODYNAMICS AIDED DESIGN OF NOVEL FERRITIC ALLOYS}

Ying Yang, Tianyi Chen, Lizhen Tan

Date Published: June 30, 2016

Prepared by

OAK RIDGE NATIONAL LABORATORY

Oak Ridge, TN 37831-6283

managed by

UT-BATTELLE, LLC

for the

US DEPARTMENT OF ENERGY

under contract DE-AC05-00OR22725 



\section{CONTENTS}

Page

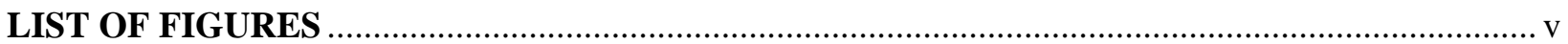

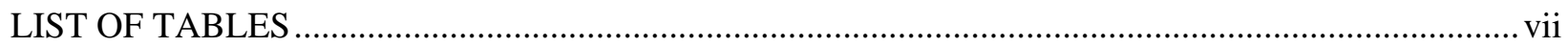

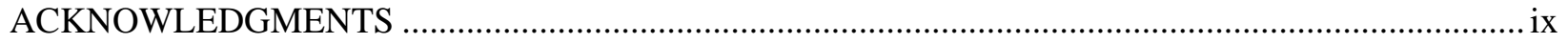

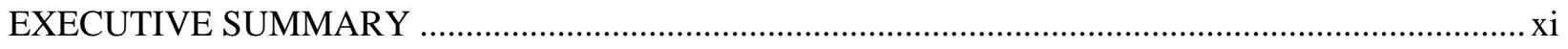

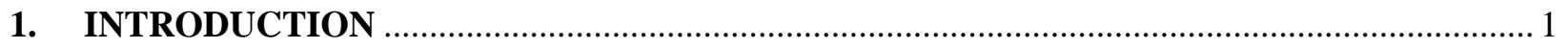

2. COMPUTATIONAL THERMODYNAMICS AIDED ALLOY DESIGN .............................. 2

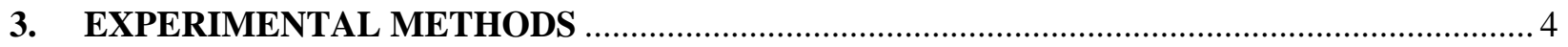

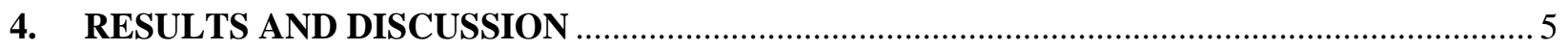

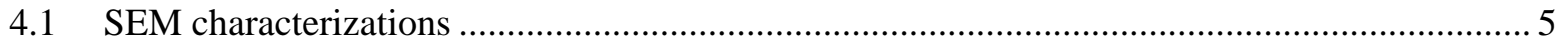

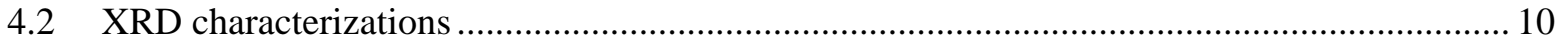

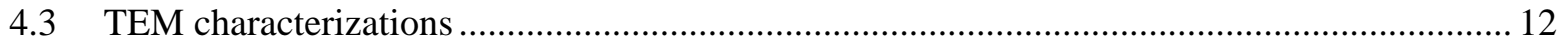

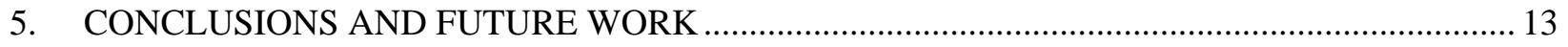

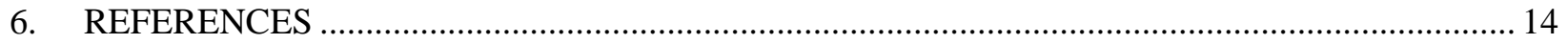





\section{LIST OF FIGURES}

Figure 1. Calculated liquidus surface of (a)Fe-Cr-Zr and (b)Fe-Ni-Zr system......................................... 2

Figure 2. Isopleth section in the Fe-Cr-Ni-Zr system (a) fixed $\mathrm{Cr}$ at $13 \mathrm{at} \%$ and $\mathrm{Zr}$ at $33.3 \mathrm{at} \%$, (b) fixed $\mathrm{Cr}$ at 13 at\% and $\mathrm{Ni}$ at 5 at\%.

Figure 3. Fe-Cr-Ni-Zr isothermal section at $1000^{\circ} \mathrm{C}$ (black line) and $700{ }^{\circ} \mathrm{C}$ (red line) with $\mathrm{Cr}$ concentration being fixed at $12 \mathrm{wt} \%$. The symbel denotes the alloy composition for experimental study.

Figure 4. BSE images of the four samples, (a) Z3N3, (b)Z6N5, (c)Z3N7 and (d)Z6N9, annealed at $700{ }^{\circ} \mathrm{C}$ for 1275 hours.

Figure 5. BSE images of the four samples, (a) Z3N3, (b)Z6N5, (c)Z3N7 and (d)Z6N9, annealed at $1000{ }^{\circ} \mathrm{C}$ for 336 hours.

Figure 6. EDS mappings of Z3N3, annealed at $700{ }^{\circ} \mathrm{C}$ for 1275 hours. (a) BSE image of the mapped region. (b) Fe mapping using Fe K-edge. (c) Cr mapping using $\mathrm{Cr}$ K-edge. (d) Ni mapping using Ni K-edge. (e) Zr mapping using Zr L-edge...

Figure 7. EDS mappings of Z3N7, annealed at $700{ }^{\circ} \mathrm{C}$ for 1275 hours. (a) BSE image of the mapped region. (b) Fe mapping using Fe K-edge. (c) Cr mapping using Cr K-edge. (d) Ni mapping using Ni K-edge. (e) Zr mapping using Zr L-edge...

Figure 8. EDS mappings of Z6N5, annealed at $700{ }^{\circ} \mathrm{C}$ for 1275 hours. (a) BSE image of the mapped region. (b) Fe mapping using Fe K-edge. (c) Cr mapping using Cr K-edge. (d) $\mathrm{Ni}$ mapping using Ni K-edge. (e) Zr mapping using Zr L-edge.....

Figure 9. EDS mappings of Z6N9, annealed at $700{ }^{\circ} \mathrm{C}$ for 1275 hours. (a) BSE image of the mapped region. (b) Fe mapping using Fe K-edge. (c) Cr mapping using Cr K-edge. (d) Ni mapping using Ni K-edge. (e) Zr mapping using Zr L-edge.

Figure 10. (a) BSE image from Z6N9 sample annealed at $700{ }^{\circ} \mathrm{C}$ for 1275 hours. (b-d), EDS spectrums collected from the sites labeled as B, C and D in (a), respectively. The atomic percentages determined from Fe K-edge, Cr K-edge, Ni K-edge and Zr L-edge were printed on each spectrum.

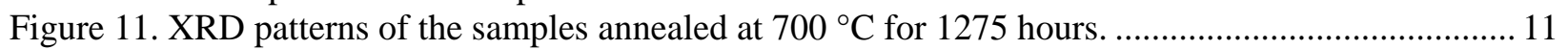

Figure 12. XRD patterns of the samples annealed at $1000{ }^{\circ} \mathrm{C}$ for 336 hours. 11

Figure 13. (a) A TEM bright-field image of the Z3N7 sample annealed at $700{ }^{\circ} \mathrm{C}$ for 1275 hours.

(b-e) SAD patterns of the grains labeled as B-E in (a), respectively. 12 



\section{LIST OF TABLES}

Table 1. Nominal Compositions of the materials in this study (atomic \%), ............................................ 4

Table 2. Chemical compositions of each sample annealed at $700{ }^{\circ} \mathrm{C}$ for 1275 hours surveyed by EDS with SEM (atomic \%).

Table 3. Chemical compositions of different phases in the Z3N7 sample annealed at $700{ }^{\circ} \mathrm{C}$ for 1275 hours. 



\section{ACKNOWLEDGMENTS}

This research was sponsored by the U.S. Department of Energy (DOE), Office of Nuclear Energy (NE), the Nuclear Energy Enabling Technologies (NEET) program Reactor Materials FY 2015 Award. We gratefully acknowledge the support provided by Sue Lesica of DOE-NE and Stuart Maloy of Los Alamos National Laboratory.

The authors are grateful to David Harper and Tom Geer of Oak Ridge National Laboratory (ORNL) for alloy and sample preparation. Philip Maziasz of ORNL is appreciated for technical review of this report. 



\section{EXECUTIVE SUMMARY}

Advanced nuclear reactors as well as the life extension of light water reactors require advanced alloys capable of satisfactory operation up to neutron damage levels approaching 200 displacements per atom (dpa). Extensive studies, including fundamental theories, have demonstrated the superior resistance to radiation-induced swelling in ferritic steels, primarily inherited from their body-centered cubic (bcc) structure. This study aims at developing nanoprecipitates strengthened advanced ferritic alloys for advanced nuclear reactor applications. To be more specific, this study aims at enhancing the ability for amorphization of $\mathrm{Fe}_{2} \mathrm{Zr}$-based nanoprecipitates in the Fe-Cr-Zr alloys through smart alloying strategy, and thereby promote the crystalline $\rightarrow$ amorphous transformation of these precipitates under irradiation.

With the aid of computational thermodynamics, $\mathrm{Ni}$ was identified to suppress the liquidus temperature of $\mathrm{Fe}_{2} \mathrm{Zr}$ and four $\mathrm{Fe}-\mathrm{Cr}-\mathrm{Ni}-\mathrm{Zr}$ alloys were designed to study the Ni effect on the phase stability of $\mathrm{Fe}_{2} \mathrm{Zr}$ laves_phase. These alloys were fabricated through traditional arc-metling, followed by annealing at 1000 ${ }^{\circ} \mathrm{C}$ for 336 hours and $700{ }^{\circ} \mathrm{C}$ for 1275 hours. The microstructure were examined and characterized by SEM BSE image, EDS compositional mapping and point scan, XRD and TEM analysis. The major results were summarized below:

1) For investigated alloys with $12 \mathrm{wt} \% \mathrm{Cr}, 3 \sim 6 \mathrm{wt} \% \mathrm{Zr}$ and $3 \sim 9 \mathrm{wt} \% \mathrm{Ni}$, the phases in equilibrium with the BCC phase are $\mathrm{C} 15$ Laves phase, $\mathrm{Fe}_{23} \mathrm{Zr}_{6}$ phase. The volume fraction of intermetallic phases increases with $\mathrm{Ni}$ and $\mathrm{Zr}$ contents.

2) Instead of $(\mathrm{Fe}, \mathrm{Cr})_{2} \mathrm{Zr} \mathrm{C} 14$ _Laves phase, Ni stabilizes the C15_Laves structure in Fe-Cr-Ni-Zr alloys by substituting $\mathrm{Fe}$ and $\mathrm{Cr}$ atoms with $\mathrm{Ni}$ atoms in the first sublattice.

3) $\mathrm{Fe}_{23} \mathrm{Zr}_{6}$, that is metastable in the Fe-Cr-Zr ternary, is also stabilized by Ni addition.

4) $\mathrm{Ni}_{7} \mathrm{Zr}_{2}$ phase was observed in samples with high $\mathrm{Ni} / \mathrm{Zr}$ ratio. Extensive solubility of $\mathrm{Fe}$ was identified in the phase.

The microstructural and composition results obtained from this study will be incorportated into the the Fe-Cr-Ni-Zr database. The current samples will be subjected to ion irradiaition to be compared with those results for Fe-Cr-Zr alloys. Additional alloys will be designed to form (Fe,Cr,Ni) ${ }_{2} \mathrm{Zr}$ nanoprecipitates for further studies. 



\section{INTRODUCTION}

Advanced nuclear reactors as well as the life extension of light water reactors require advanced alloys capable of satisfactory operation up to neutron damage levels approaching 200 displacements per atom (dpa)[1]. Extensive studies, including fundamental theories, have demonstrated the superior resistance to radiation-induced swelling in ferritic steels, primarily inherited from their body-centered cubic (bcc) structure [2]. In our previous work [3], novel Fe-Cr-Zr ferritic alloys strengthened by $\mathrm{Fe}_{2} \mathrm{Zr} \_$based Laves_phase precipitates show superior strength, ductility and creep resistance at high temperature, however, a consistent improvement on their irradiation resistance data have yet to be achieved. Amorphization of $\mathrm{Fe}_{2} \mathrm{Zr}$ Laves phase has been frequently attained through mechanical alloying [4], sputtering deposition [5], and ion irradiation [6]. In a recent in situ ion irradiation study of a binary bcc( $\mathrm{Fe}) / \mathrm{Fe}_{2} \mathrm{Zr}$ nanocomposite, irradiation-induced amorphization of $\mathrm{Fe}_{2} \mathrm{Zr}$ has been directly observed [7] under TEM. It was found that the density and size of the irradiation-induced defects such as dislocation loops is drastically low in the adjacent bcc matrix phase. In situ TEM revealed that the dislocation loops in $\mathrm{Bcc}(\mathrm{Fe})$ were confined by the crystal/amorphous interfaces and kept migrating to annihilate other defects. The amorphous $\mathrm{Fe}_{2} \mathrm{Zr}$ nanolayer was also suggested as potential traps of the radiation-induced defects due to its excess free volume [7]. This study lends us new insights on the design of irradiation resistant Fe-CrZr ferritic alloys.

Unlike the $\mathrm{Fe}_{2} \mathrm{Zr}$ nanolayer in the $\mathrm{Fe}-\mathrm{Zr}$ binary in literature [7], the $\mathrm{Fe}_{2} \mathrm{Zr}$ nanoprecpitates formed in our Fe-Cr-Zr-based alloys still remain crystalline feature after irradiation. Preliminary TEM results clearly show the diffraction spots from crystalline Laves phase [8]. The lack of complete amorphization in our work can be attributed to several factors such as appreciable solubility of $\mathrm{Cr}$ in the $\mathrm{Fe}_{2} \mathrm{Zr}$ phase, nonuniform sizes of $\mathrm{Fe}_{2} \mathrm{Zr}$ particles, and unfavorable irradiation conditions. This incomplete amorphization can have a role in explaining the large scattering of the hardening data in the irradiated Fe-Cr-Zr-based (Z-) alloys [8]. While we could manipulate the irradiation conditions for complete amorphization, we propose to enhance the ability for amorphization of $\mathrm{Fe}_{2} \mathrm{Zr}$-based nanoprecipitates in the $\mathrm{Fe}-\mathrm{Cr}$ - $\mathrm{Zr}$ alloys through smart alloying strategy, and thereby promote the crystalline $\rightarrow$ amorphous transformation of these precipitates under irradiation. With the enhanced ability for amorphization, the precipitates can better tolerate different irradiation conditions and size difference, and reach a complete crystalline $\rightarrow$ amorphous transformation.

The challenge is to identify smart alloying strategy that can promote the amorphous-forming ability of the $(\mathrm{Fe}, \mathrm{Cr})_{2} \mathrm{Zr}$ Laves precipitates. The concept of the amorphous-forming ability is borrowed from the glassforming ability (GFA) of a melt [9]. While it is often evaluated by the critical cooling rate required to bypass the formation of crystals, it is primarily determined by the alloy composition. The GFA of an alloy composition has been gauged using the criterion of $T_{x} /\left(T_{\mathrm{g}}+T_{1}\right)$, where $T_{x}, T_{l}$ and $T_{g}$ are the onset crystallization (solidus), liquidus and glass transition temperature, respectively. The larger the value of $T_{x} /$ $\left(T_{\mathrm{g}}+T_{1}\right)$, the higher the GFA. For a particular alloy system, the $T_{g}$ does not differ very much from one composition to the other. In contrast, the $T_{x}$ and $T_{l}$ can change significantly with composition as suggested by solidus and liquidus of a phase diagram. Clearly, by reducing $T_{l}$, i.e., suppressing the liquidus temperature, the GFA can be improved. Extensive studies have suggested that the high GFA is closely related to large atomic size mismatch, large negative enthalpy of formation and complex crystal structure [10]. These conditions are often manifested in systems with low lying liquid surface, such as eutectic reaction [11-13]. 


\section{COMPUTATIONAL THERMODYNAMICS AIDED ALLOY DESIGN}

The selection of alloying elements and the design of experimental alloy compositions were aided by computational thermodynamics. The essence of computational thermodynamics, i.e., the CALPHAD (CALculation of PHAse Diagram) approach [14], was to construct phase diagrams of multicomponent systems based on well assessed thermodynamic functions of Gibbs energy of phases. In the prior NEET project, a thermodynamic database containing major elements of $\mathrm{Fe}, \mathrm{Cr}, \mathrm{Zr}$ and minor elements of Mo, W, $\mathrm{Si}, \mathrm{Nb}, \mathrm{C}$ has been developed and validated by experimental data [8]. Ni were also included in this database but need to be further validated by experimental data. This database is used as a starting point for alloy design. The experimental data generated from these alloys will be used to validate the calculated results.

Computation screening on isopleth of $\mathrm{Fe}_{2} \mathrm{Zr}-\mathrm{Fe}_{2} \mathrm{X}(\mathrm{X}=\mathrm{Mo}, \mathrm{W}$, and $\mathrm{Nb}$ ) found all these alloying elements increase the liquidus temperature of $\mathrm{Fe}_{2} \mathrm{Zr}$. In contrast, Ni addition into the $\mathrm{Fe}-\mathrm{Cr}$ system decreases the liquidus temperature of $\mathrm{Fe}_{2} \mathrm{Zr}$. The major difference between $\mathrm{Ni}$ and other alloying elements such as $\mathrm{Mo}, \mathrm{Nb}$ and $\mathrm{W}$ is that the former mainly substitutes the Fe in the first sublattice while the others substitute the $\mathrm{Zr}$ in the second sublattice. Therefore, $\mathrm{Ni}$ is selected as an element that has potential to promote the amorphous forming ability of $\mathrm{Fe}_{2} \mathrm{Zr}$. Based on the preliminary Fe-Cr-Zr-Ni database, we calculated the liquidus surface of the Fe-Cr-Zr and Fe-Ni-Zr and compared them side by side in Figure 1 (a) and (b). The results suggest the Fe-Ni-Zr liquidus surface is more suppressed than that of Fe-Cr-Zr.
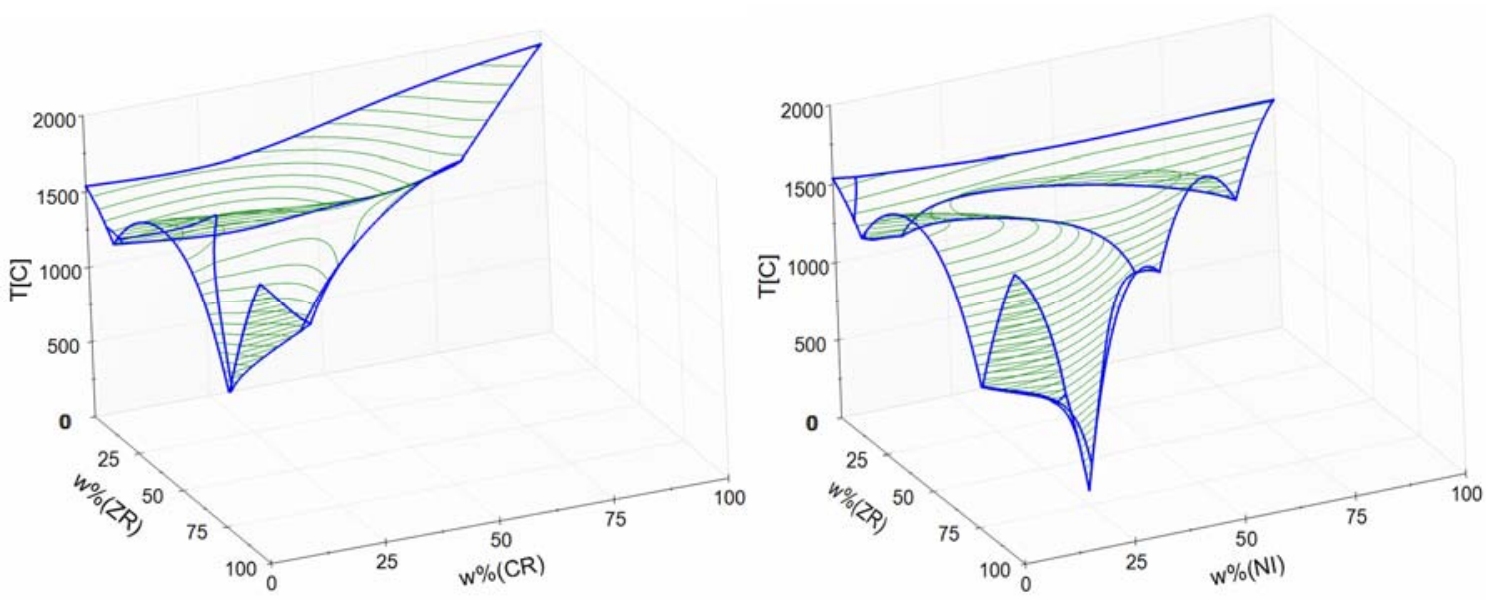

Figure 1. Calculated liquidus surface of (a)Fe-Cr-Zr and (b)Fe-Ni-Zr system

While it is difficult to visualize the liquidus surface in a quarternary system, we can plot different isopleth sections to see how Ni affects liquidus surface. Two isopleth section in the Fe-rich region were calculated and plotted in Figure 2 (a) and (b). One is the isopleth section with fixed Zr concentration at 33.3 at\%. This isopleth essentially plots the phase diagram along $\mathrm{M}_{2} \mathrm{Zr}(\mathrm{M}=\mathrm{Fe}, \mathrm{Cr}, \mathrm{Ni})$ direction. We also need to fix another variable to obtain the 2D diagram. The Cr concentration is fixed at $12 \mathrm{wt} \%$, as this amount of $\mathrm{Cr}$ is desired to reach desirable corrosion resistance. The results shows when increasing Ni concentration, the temperature of liquidus surface is decreasing. The second isopleth plots the phase diagram with fixed $\mathrm{Cr}$ and $\mathrm{Ni}$ concentration, in which a deep eutectic between $\operatorname{Bcc}(\mathrm{Fe})$ and Laves_C15 presents. Thermodynamic calculation suggests that adding Ni to the Fe-Cr-Zr alloy suppresses the liquidus surface in Fe-rich region, thus fufill our design goal. However, these results are exclusively from calculation. We 
need to validate the calculation results from experiments. Isothermal sections of Fe-Cr-Ni-Zr at 1000 and $700^{\circ} \mathrm{C}$ were calculated with fixed $\mathrm{Cr}$ concention at $12 \mathrm{wt} \%$. The calculated results are shown in Figure 3 with the red line denoting phase boundaries at $700^{\circ} \mathrm{C}$, and the black line for $1000^{\circ} \mathrm{C}$.
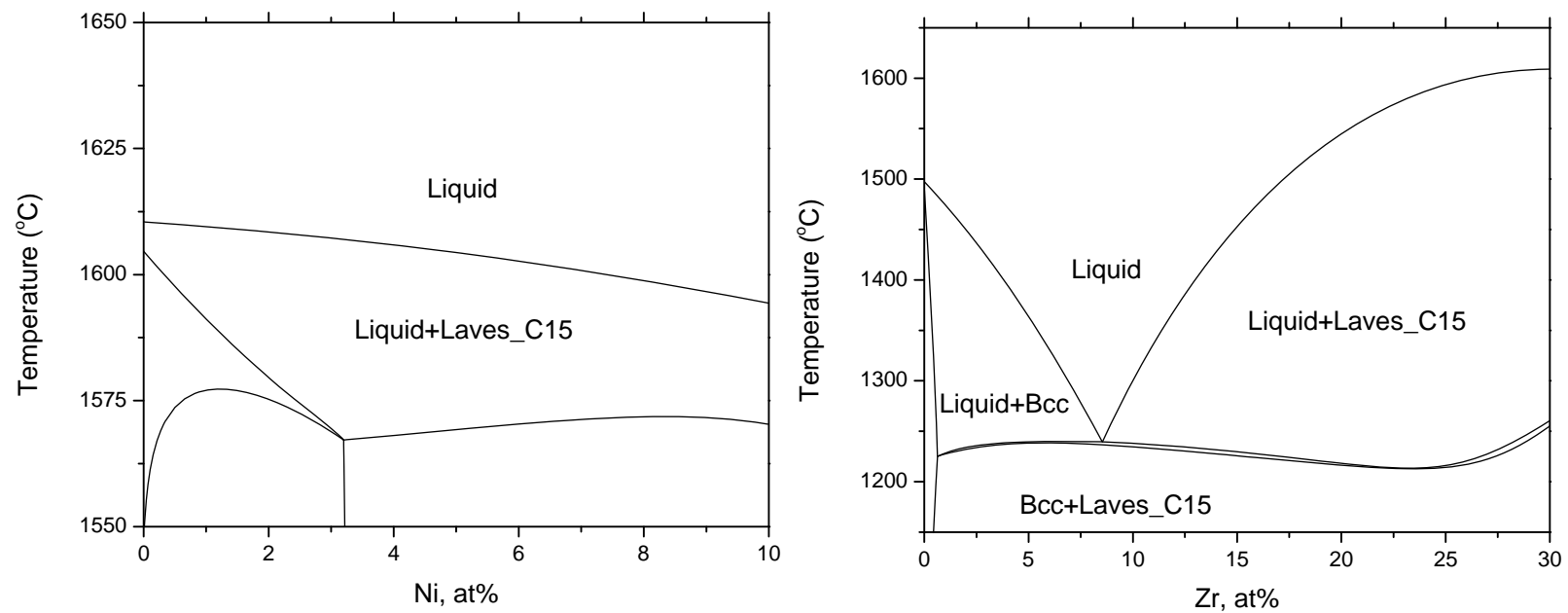

Figure 2. Isopleth section in the Fe-Cr-Ni-Zr system (a) fixed $\mathrm{Cr}$ at 13 at \% and $\mathrm{Zr}$ at 33.3 at\%, (b) fixed $\mathrm{Cr}$ at 13 at\% and $\mathrm{Ni}$ at 5 at\%.

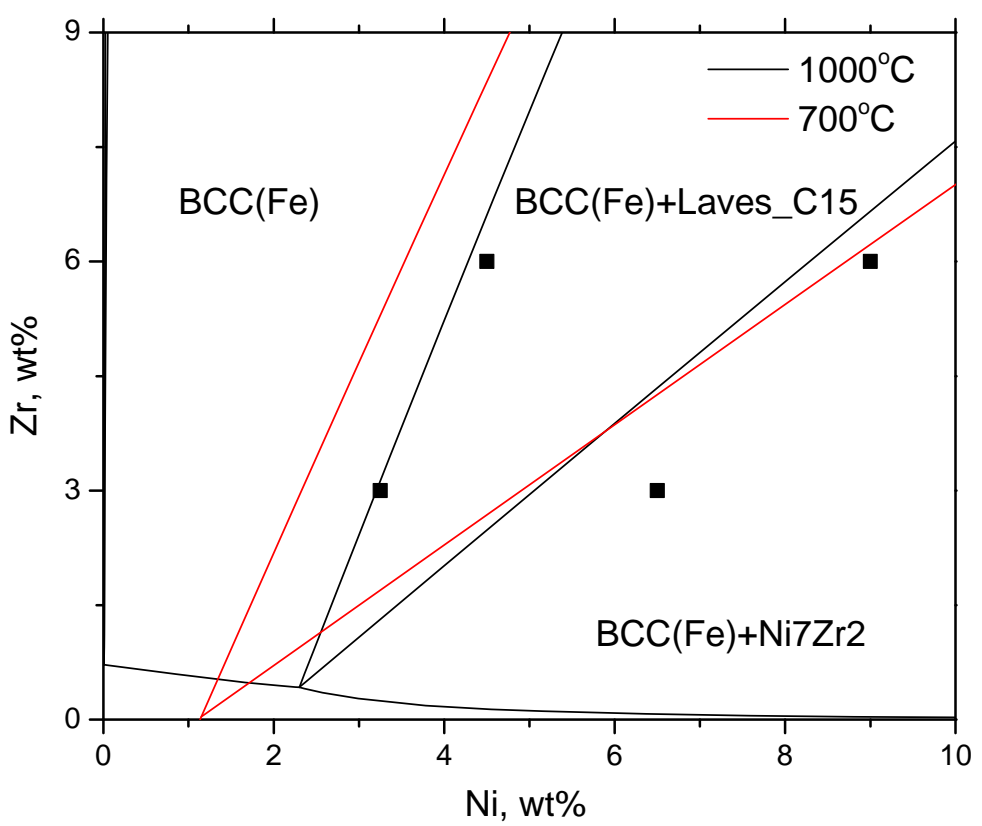

Figure 3. Fe-Cr-Ni-Zr isothermal section at $1000{ }^{\circ} \mathrm{C}$ (black line) and $700{ }^{\circ} \mathrm{C}$ (red line) with $\mathrm{Cr}$ concentration being fixed at $12 \mathrm{wt} \%$. The symbel denotes the alloy composition for experimental study.

Four alloy compositions close to the phase boundary were selected for experimental study including 
isothermal annealing at 1000 and $700{ }^{\circ} \mathrm{C}$. Annealing at two temperatures can help us to get an idea how stable the phase boundary vs temperature and whether to introduce an entropy term when modeling the Gibbs energy function. The nominal alloy composition in wt $\%$ and at $\%$ are listed in Table 1.

Table 1. Nominal Compositions of the materials in this study (atomic \%).

\begin{tabular}{|l|l|l|l|l|l|l|l|l|}
\hline \multirow{2}{*}{} & \multicolumn{2}{|c|}{$\mathrm{Fe}$} & \multicolumn{2}{c|}{$\mathrm{Cr}$} & \multicolumn{2}{c|}{$\mathrm{Ni}$} & \multicolumn{2}{c|}{$\mathrm{Zr}$} \\
\cline { 2 - 9 } & $\mathrm{At} \%$ & $\mathrm{Wt} \%$ & $\mathrm{At} \%$ & $\mathrm{Wt} \%$ & $\mathrm{At} \%$ & $\mathrm{Wt} \%$ & $\mathrm{At} \%$ & $\mathrm{Wt} \%$ \\
\hline Z3N3 & 82.11 & 81.75 & 12.94 & 12 & 3.11 & 3.25 & 1.84 & 3 \\
\hline Z3N7 & 78.97 & 78.5 & 12.96 & 12 & 6.22 & 6.5 & 1.85 & 3 \\
\hline Z6N5 & 78.81 & 77.5 & 13.11 & 12 & 4.35 & 4.5 & 3.73 & 6 \\
\hline Z6N9 & 74.40 & 73 & 13.13 & 12 & 8.73 & 9 & 3.74 & 6 \\
\hline
\end{tabular}

\section{EXPERIMENTAL METHODS}

The starting materials are elemental $\mathrm{Fe}, \mathrm{Cr}, \mathrm{Zr}$ and $\mathrm{Ni}$ with purity level as $>99.904 \%,>99.978 \%$, $>99.2 \%$ and $>99.15 \%$, respectively. Small buttons of each alloy, with a target weight of $10 \mathrm{~g}$, were produced by arc-melting in a pure Ar atmosphere. The total weight loss was less than $0.01 \%$, therefore, the alloys were considered as having the nominal compositions.

Each button was cut into three pieces. One of them was used for as-cast microstructure analysis and the other two were capsuled in evacuated quartz tubes and annealed at $1000{ }^{\circ} \mathrm{C}$ for 336 hours and $700{ }^{\circ} \mathrm{C}$ for 1275 hours, respectively. After the heat treatment, the annealed samples were quenched to room temperature with water.

The samples were mechanically polished for scanning electron microscope (SEM) based characterizations. A JEOL 6500F and a Hitachi S4800 SEM were used for backscattering electron microscopy (BSE) and energy-dispersive X-ray spectroscopy (EDS). Both SEM have the field emission systems and the guns were operated at acceleration voltages of $20 \mathrm{kV}$. X-ray diffraction (XRD) analysis was also conducted on the annealed samples for phase identification. A Bruker D2 phaser with $\mathrm{Cu} \mathrm{K} \alpha$ radiation ( $\lambda=1.54056 \AA$ ) was used to carry out the scanning over a range of $30^{\circ}-60^{\circ}$ in $2 \theta$. The step size was set to be $0.02^{\circ}$. At each step, the diffracted X-ray was collected for 40 seconds. Transmission electron microscopy (TEM) was used to characterize one of the four samples. Selected area electron diffraction (SAD) patterns were used to furtherly confirm the phase identifications. More accurate chemical compositions of each phase were obtained using EDS. The TEM used in this study is a JEOL 2100F operated at $200 \mathrm{kV}$. TEM samples were prepared using focused-ion-beam (FIB) technique with a FEI versa 3D SEM/FIB dual beam system. 


\section{RESULTS AND DISCUSSION}

\subsection{SEM characterizations}

The SEM BSE image and EDS were used to analyze the morphology and composition of phases in the invesitigated alloys. Figures 4 and 5 show the BSE images of the four samples annealed at $700{ }^{\circ} \mathrm{C}$ and 1000 ${ }^{\circ} \mathrm{C}$ for 1275 hours, respectively. The Fe-based matrix has a darker contrast while the intermetallic phases, containing higher level of Zr, are brighter in the BSE images. In Figure 4, eutectic microstructures with fine features of $\sim 0.5 \mu \mathrm{m}$ (for instance the inset of Figure 4c) were observed in the samples annealed at $700{ }^{\circ} \mathrm{C}$. Based on the BSE image analysis results, the fractions of the intermetallic phases in all the four samples are estimated to be $10 \%, 13 \%, 20 \%$ and $20 \%$ for Z3N3, Z3N7, Z6N5 and Z6N9 samples, respectively. Higher $\mathrm{Zr}$ content leads to higher fraction of intermetallic phases. EDS results show that the compositions of three intermetallic phases, namely $\mathrm{Fe}_{2} \mathrm{Zr}, \mathrm{Fe}_{23} \mathrm{Zr}_{6}$ and $\mathrm{Ni}_{7} \mathrm{Zr}_{2}$, observed in the set of $\mathrm{Fe}-\mathrm{Cr}-\mathrm{Zr}-\mathrm{Ni}$ samples.
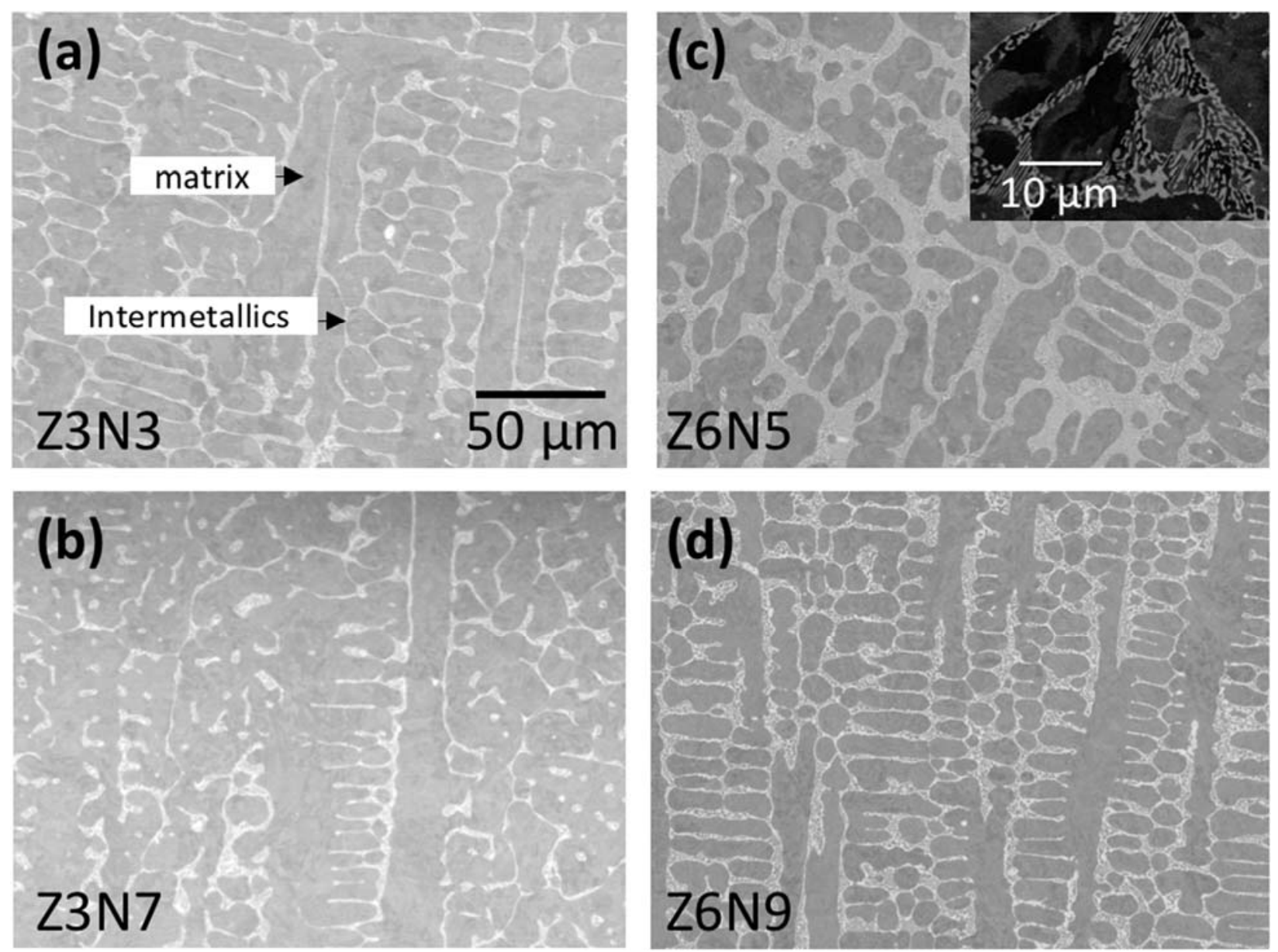

Figure 4. BSE images of the four samples, (a) Z3N3, (b)Z6N5, (c)Z3N7 and (d)Z6N9, annealed at $700{ }^{\circ} \mathrm{C}$ for 1275 hours.

The microstructure of the samples after annealing at $1000{ }^{\circ} \mathrm{C}$ for 336 hours are shown in Figure 5. In comparison with the micrographs in Figure 4, no significant change of the overall fraction of the intermetallic phases were found from the estimations on the samples annealed at $700{ }^{\circ} \mathrm{C}$. This suggests that the phase boundaries do not significantly change over the range of temperatures. However, eutectic 
microstructures after annealed at $1000{ }^{\circ} \mathrm{C}$ show coarser features than those at $700^{\circ} \mathrm{C}$. This difference is demonstrated by the comparison between the inserted figures in Figure 4c and Figure 5d. This result suggests that the kinetics of the alloys at $700^{\circ} \mathrm{C}$ is not fast enough and the fine eutectic in the as-cast microstructure still remains after 1275-hour annealing. In contrast, coarsening due to the fact kinetics at $1000^{\circ} \mathrm{C}$ leads to the microsturuture more towards the equilibrium state. However, even for the samples annealed at $1000{ }^{\circ} \mathrm{C}$, fine features were still visible in Figure $5 \mathrm{~b}$ and $5 \mathrm{~d}$, suggesting that equilibrium was not fully reached even after thermal annealing at $1000{ }^{\circ} \mathrm{C}$ for 336 hours.
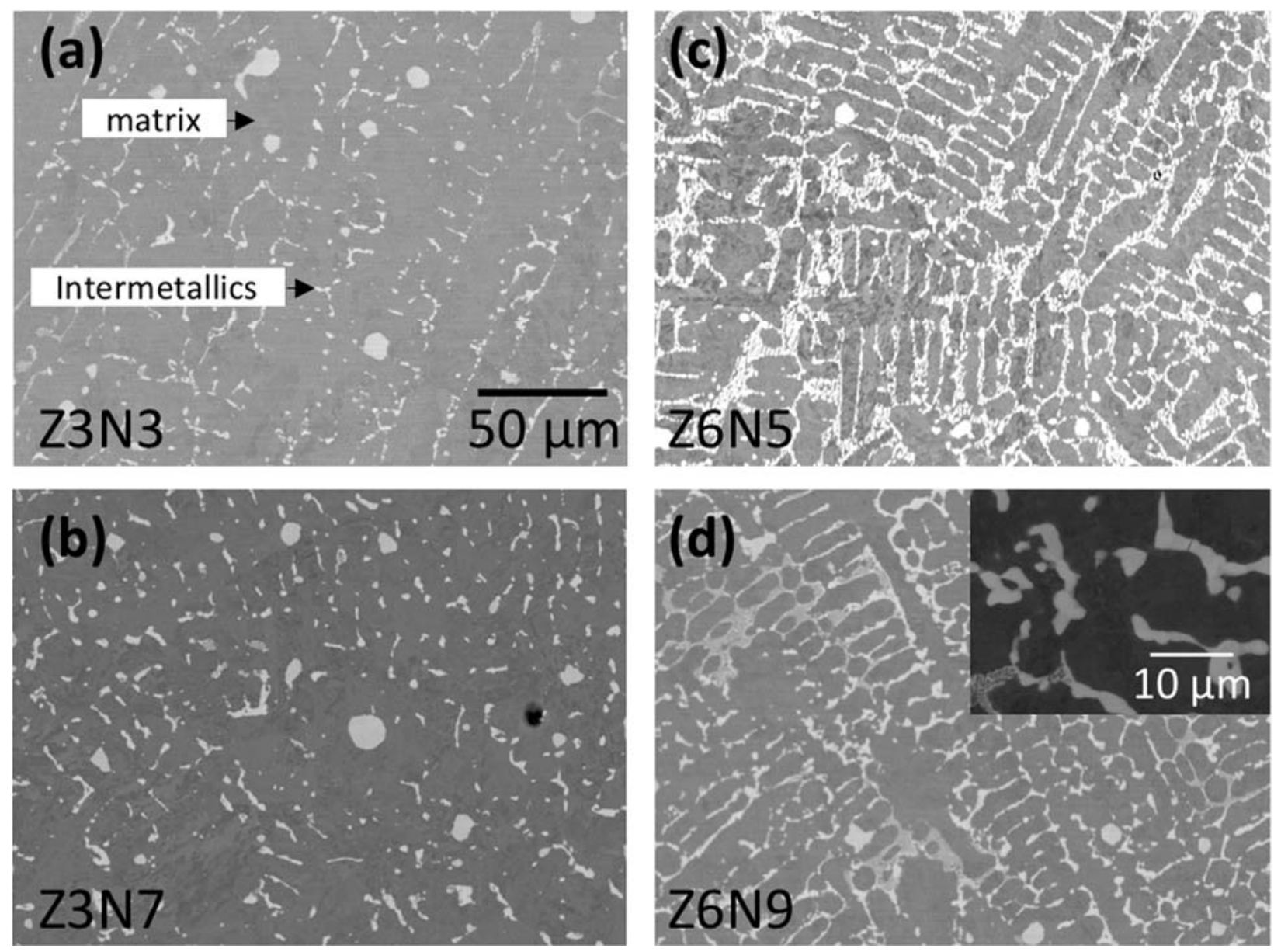

Figure 5. BSE images of the four samples, (a) Z3N3, (b)Z6N5, (c)Z3N7 and (d)Z6N9, annealed at $1000{ }^{\circ} \mathrm{C}$ for 336 hours.

The chemical compositions of the samples were studied using SEM EDS techniques. Figure 6-9 show EDS mapping results of the samples of Z3N3, Z3N7, Z6N5 and Z6N9, respectively, which were annealed at $700{ }^{\circ} \mathrm{C}$. The elemental distributions of $\mathrm{Fe}, \mathrm{Cr}, \mathrm{Zr}$ and Ni were obtained using FeK, CrK, $\mathrm{ZrL}$ and NiK signals, respectively. Overall, the intermetallic phases formed in the set of quaternary alloys are rich in $\mathrm{Zr}$ and $\mathrm{Ni}$, while the matrix phase is rich in $\mathrm{Fe}$ and $\mathrm{Cr}$ and lean in $\mathrm{Zr}$ and $\mathrm{Ni}$. Among the intermetallic phases, $\mathrm{Ni}$ and $\mathrm{Zr}$ are not uniformly distributed, as seen from Figure 6-9 in (d) and (e). Particularly, the Ni concentrated phases are very obvious, suggesting the presence of a Ni-dominant phase. Qualitatively, the fraction of the Ni-dominant phase is correlated to the ratio of the compositions of $\mathrm{Ni}$ and $\mathrm{Zr}$ rather than the absolute compositions of Zr. None of the Ni-dominant phase was observed in the sample of Z6N5, with the 
lowest ratio of $\mathrm{Ni}$ to $\mathrm{Zr}$. On the other hand, the Ni-dominant phase was more frequently observed in the samples of Z6N9 and Z3N7, where the Ni-Zr ratios are higher.
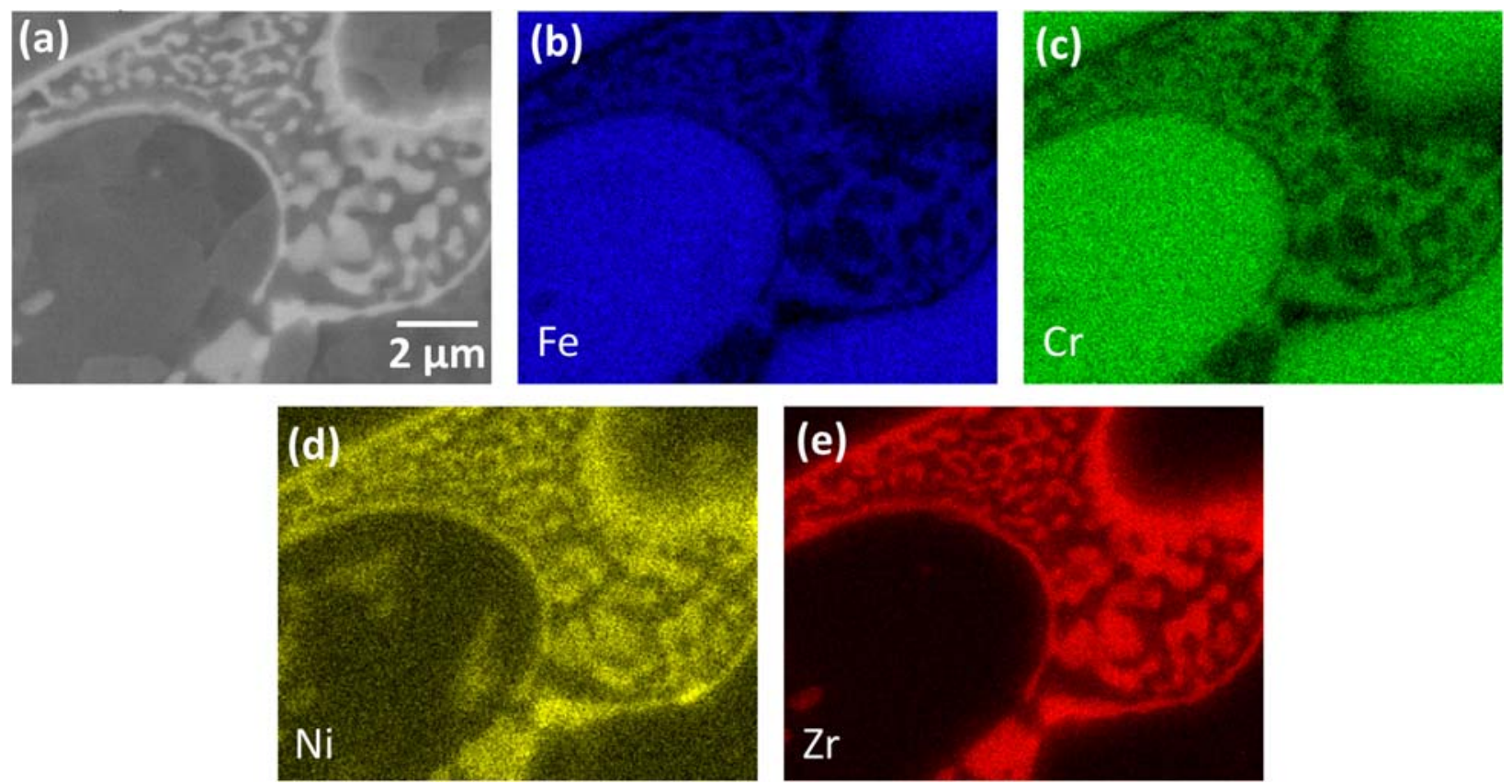

Figure 6. EDS mappings of Z3N3, annealed at $700{ }^{\circ} \mathrm{C}$ for 1275 hours. (a) BSE image of the mapped region. (b) Fe mapping using Fe K-edge. (c) Cr mapping using $\mathrm{Cr}$ K-edge. (d) Ni mapping using Ni K-edge. (e) Zr mapping using Zr L-edge.
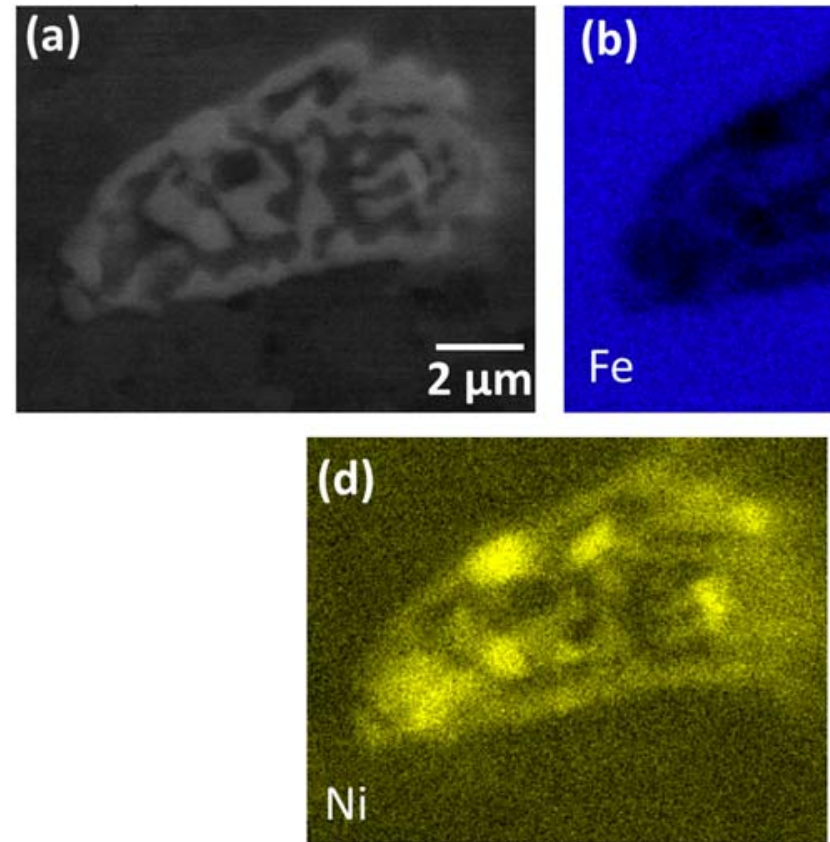
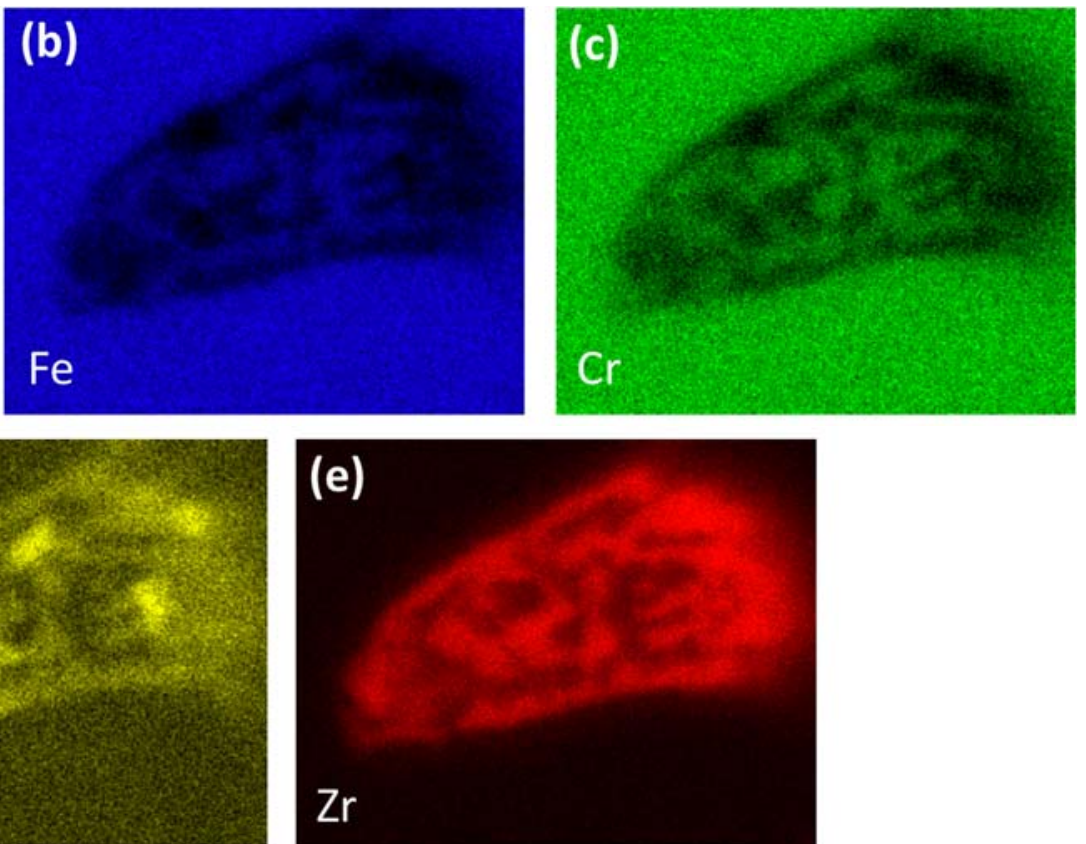

Figure 7. EDS mappings of Z3N7, annealed at $700{ }^{\circ} \mathrm{C}$ for 1275 hours. (a) BSE image of the mapped region. (b) Fe mapping using Fe K-edge. (c) Cr mapping using Cr K-edge. (d) Ni mapping using Ni K-edge. (e) Zr mapping using Zr L-edge. 

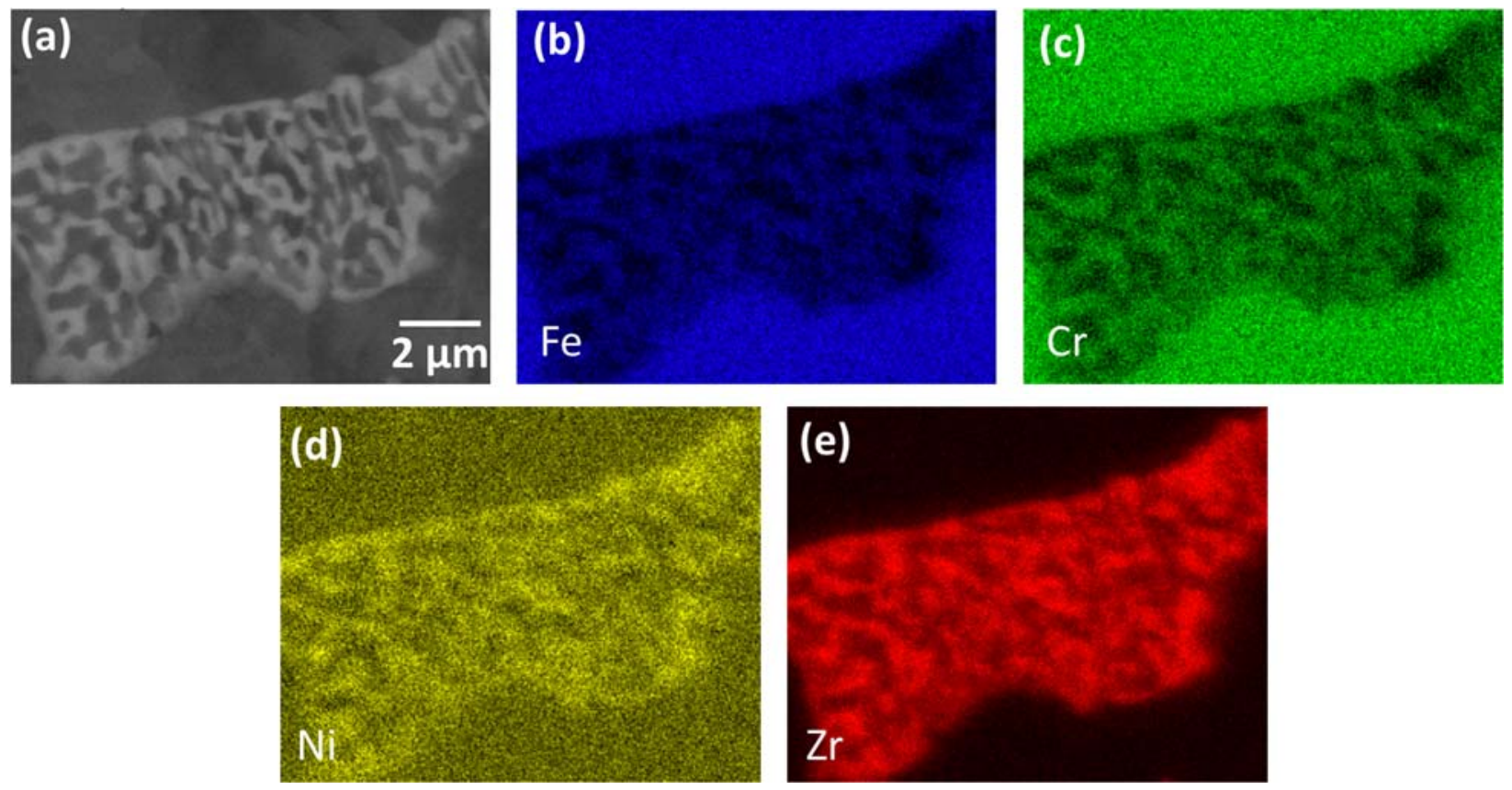

Figure 8. EDS mappings of Z6N5, annealed at $700{ }^{\circ} \mathrm{C}$ for 1275 hours. (a) BSE image of the mapped region. (b) Fe mapping using Fe K-edge. (c) Cr mapping using Cr K-edge. (d) Ni mapping using Ni K-edge. (e) Zr mapping using Zr L-edge.
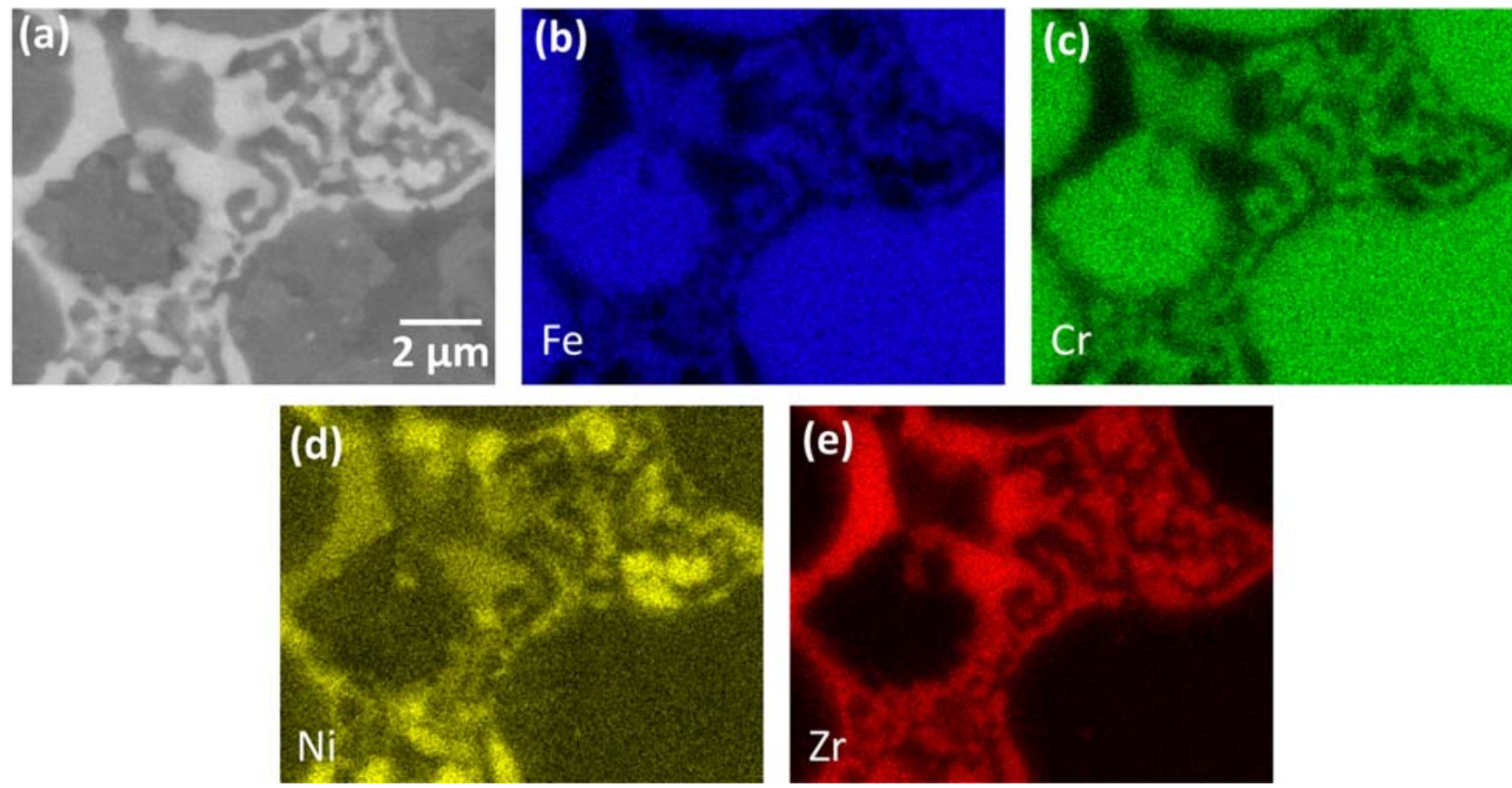

Figure 9. EDS mappings of Z6N9, annealed at $700{ }^{\circ} \mathrm{C}$ for 1275 hours. (a) BSE image of the mapped region. (b) Fe mapping using Fe K-edge. (c) Cr mapping using $\mathrm{Cr}$ K-edge. (d) Ni mapping using Ni K-edge. (e) Zr mapping using Zr L-edge. 
The results of EDS point surveys from the sample Z6N9 annealed at $700^{\circ} \mathrm{C}$ are shown in Figure 10 . The EDS spectrums obtained from the sites of B, C and D are shown in Figure 10 (b), (c), and (d), respectively. Site B is in the matrix phase, which is a Fe-Cr compound with small amount of $\mathrm{Ni}$ and $\mathrm{Zr}$ solutes, as suggested by the EDS analysis. Spectrums in Figure 10 (c) and (d) were obtained from the intermetallic phases, with the characteristic high fractions of $\mathrm{Zr}$ and Ni. Given that the feature sizes of the intermetallic phases are smaller than the interaction volume of $20 \mathrm{keV}$ electron (with the latter having a typical dimension of $\sim 5 \mu \mathrm{m}$ ), the composition estimated from sites $\mathrm{C}$ and $\mathrm{D}$ were inevitably influenced by their surroundings. Still, qualitatively, the intermetallic phase at D has a higher Ni-Zr ratio than the intermetallic phase at $\mathrm{C}$. As will be shown later, the low $\mathrm{Ni}$ phase corresponds to either $(\mathrm{Fe}, \mathrm{Ni})_{2} \mathrm{Zr}$ or $(\mathrm{Fe}, \mathrm{Ni})_{23} \mathrm{Zr}_{6}$, and the high $\mathrm{Ni}$ phase corresponds to $(\mathrm{Ni}, \mathrm{Fe})_{7} \mathrm{Zr}_{2}$. The results of EDS point surveys done with SEM on the samples annealed at $700{ }^{\circ} \mathrm{C}$ are compelled in Table 2. As will be discussed later, the EDS analysis done with SEM is not accurate due to the relatively large beam size compared with the sizes of the features of intersts. Yet, the differences in composition among the matrix and intermetallic phases are obvious.

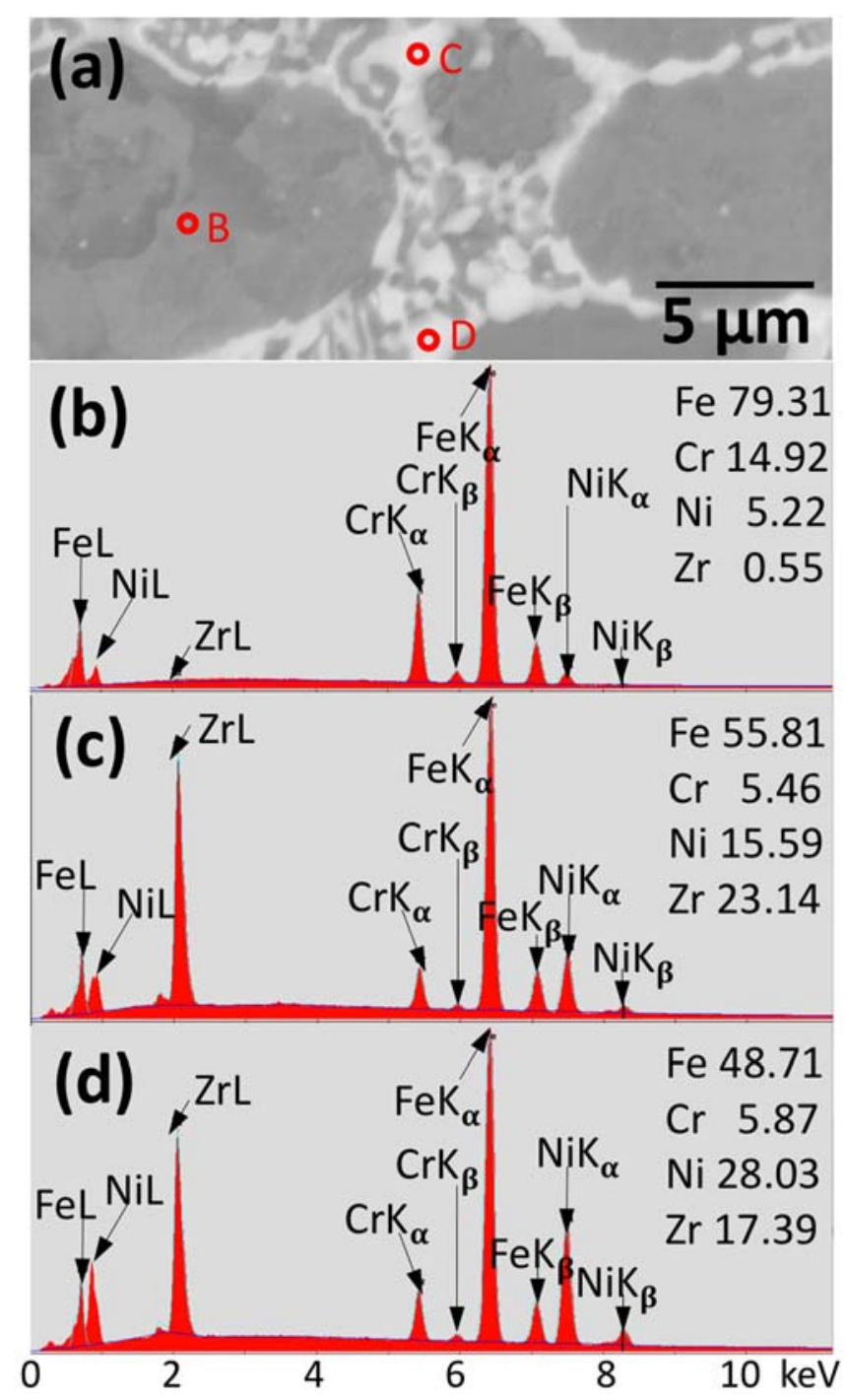

Figure 10. (a) BSE image from Z6N9 sample annealed at $700{ }^{\circ} \mathrm{C}$ for 1275 hours. (b-d), EDS spectrums collected from the sites labeled as B, C and $D$ in (a), respectively. The atomic percentages determined from $\mathrm{Fe}$ K-edge, $\mathrm{Cr}$ K-edge, Ni K-edge and $\mathrm{Zr}$ L-edge were printed on each spectrum. 
Table 2. Chemical compositions of each sample annealed at $700{ }^{\circ} \mathrm{C}$ for 1275 hours surveyed by EDS with SEM (atomic \%).

\begin{tabular}{|l|l|l|l|}
\hline & Matrix & $(\mathrm{Fe}, \mathrm{Ni})_{2} \mathrm{Zr}$ or $(\mathrm{Fe}, \mathrm{Ni})_{23} \mathrm{Zr}_{6}$ & $(\mathrm{Ni}, \mathrm{Fe})_{7} \mathrm{Zr}_{2}$ \\
\hline Z3N3 & Fe: $84.59 \pm 0.17$ & Fe: $69.92 \pm 0.52$ & Fe: $63.40 \pm 0.13$ \\
& Cr: $13.58 \pm 0.07$ & Cr: $8.84 \pm 0.42$ & Cr: $7.85 \pm 0.86$ \\
& Ni: $1.41 \pm 0.14$ & Ni: $7.49 \pm 0.34$ & Ni: $13.53 \pm 1.64$ \\
& Zr: $0.42 \pm 0.05$ & Zr: $13.75 \pm 0.43$ & Zr: $15.24 \pm 2.63$ \\
\hline Z3N7 & Fe: $80.36 \pm 0.26$ & Fe: $58.30 \pm 1.16$ & Fe: $51.26 \pm 0.62$ \\
& Cr: $13.99 \pm 0.11$ & Cr: $5.86 \pm 1.07$ & Cr: $6.35 \pm 0.55$ \\
& Ni: $5.08 \pm 0.19$ & Ni: $13.65 \pm 0.85$ & Ni: $25.04 \pm 1.68$ \\
& Zr: $0.56 \pm 0.19$ & Zr: $21.74 \pm 1.52$ & Zr: $17.36 \pm 2.85$ \\
\hline Z6N5 & Fe: $81.78 \pm 0.18$ & Fe: $67.61 \pm 1.31$ & - \\
& Cr: $14.26 \pm 0.20$ & Cr: $9.21 \pm 0.48$ & \\
& Ni: $3.55 \pm 0.47$ & Ni: $7.33 \pm 0.84$ & \\
& Zr: $0.41 \pm 0.16$ & Zr: $15.85 \pm 1.12$ & \\
& & & Fe: $49.35 \pm 2.39$ \\
& Fe: $78.37 \pm 0.79$ & Cr: $5.09 \pm 0.76$ & Cr: $6.01 \pm 1.30$ \\
& Cr: $14.81 \pm 0.06$ & Ni: $16.4 \pm 0.60$ & Ni: $27.14 \pm 1.51$ \\
& Ni: $6.06 \pm 0.55$ & Zr: $23.25 \pm 1.75$ & Zr: $17.44 \pm 2.25$ \\
& Zr: $0.58 \pm 0.04$ & & \\
\hline
\end{tabular}

\subsection{XRD characterizations}

The XRD patterns of the samples annealed at $700{ }^{\circ} \mathrm{C}$ and $1000{ }^{\circ} \mathrm{C}$ are shown in Figure 11 and 12 , respectively. The strongest peaks near $2 \theta=44.56^{\circ}$ corresponds to the (110) of body-centered-cubic (BCC) $\mathrm{Fe}-\mathrm{Cr}$, the matrix phase. The other peaks, labeled as $\mathrm{C} 15$ and $\mathrm{Fe}_{23} \mathrm{Zr}_{6}$, corresponds to the $\mathrm{Fe}_{2} \mathrm{Zr}$ Laves phase with cubic $\mathrm{C} 15$ structure and the $\mathrm{Fe}_{23} \mathrm{Zr}_{6}$ phase. The peaks corresponding to the $\mathrm{C} 15$ and $\mathrm{Fe}_{23} \mathrm{Zr}_{6}$ phases were observed in all samples subjected to both annealing conditions, suggesting that they are both stable at the temperatures of $700^{\circ} \mathrm{C}$ and $1000{ }^{\circ} \mathrm{C}$. Considering their relative peak intensity changes in different samples with variant compositions, it seems that $\mathrm{Fe}_{23} \mathrm{Zr}_{6}$ is at a higher fraction of the intermetallic phases when the material contains a smaller amount Zr. No peaks of the C14 or C36 of the Laves phase was observed under the experiment conditions of this study. A standard XRD pattern of $\mathrm{LaB}_{6}$, which was shown associated with the Z6N9 pattern in Figure 12, was used to calibrate the $2 \theta$ measurements. Using the Bragg's formula, the lattice parameters of the $\mathrm{C} 15$ Laves phase and the $\mathrm{Fe}_{23} \mathrm{Zr}_{6}$ phase were estimated to be $6.98 \AA$ and $11.69 \AA$, respectively. 


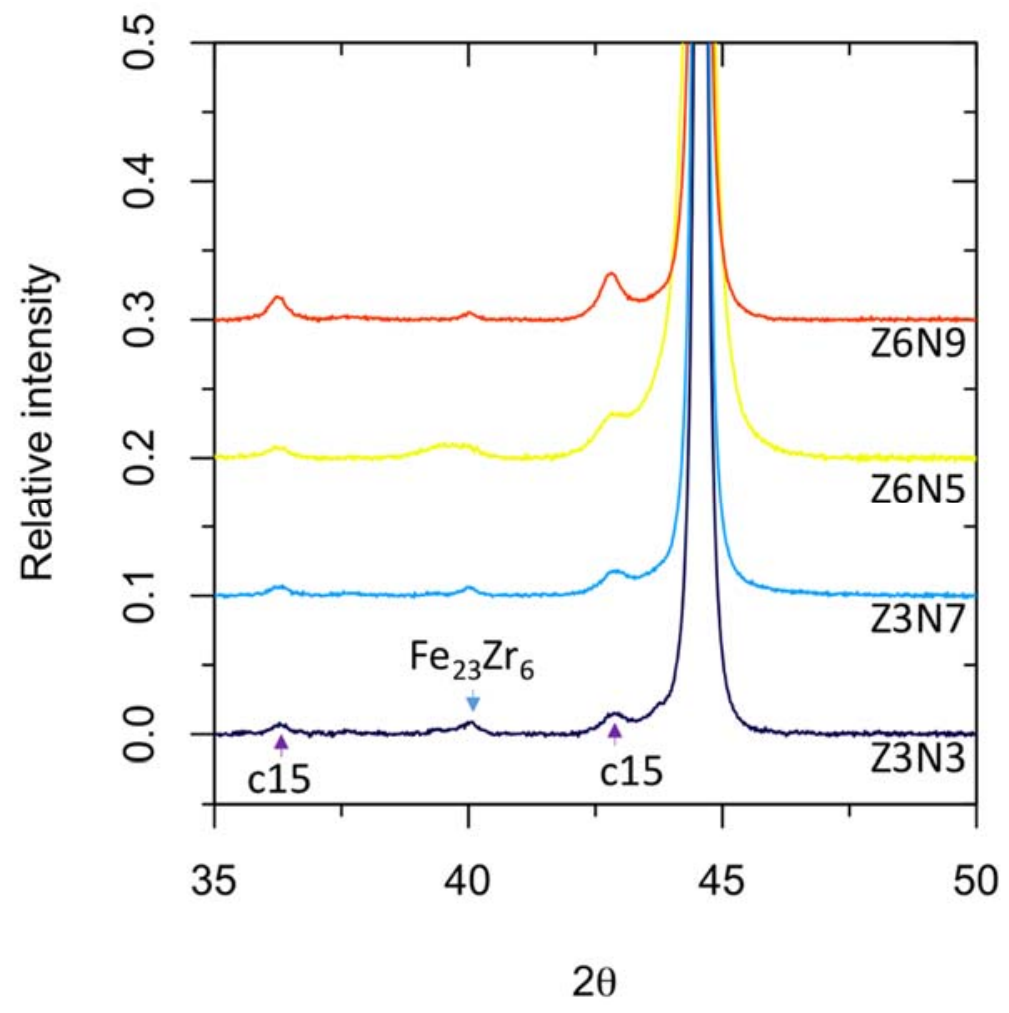

Figure 11. XRD patterns of the samples annealed at $700{ }^{\circ} \mathrm{C}$ for 1275 hours.

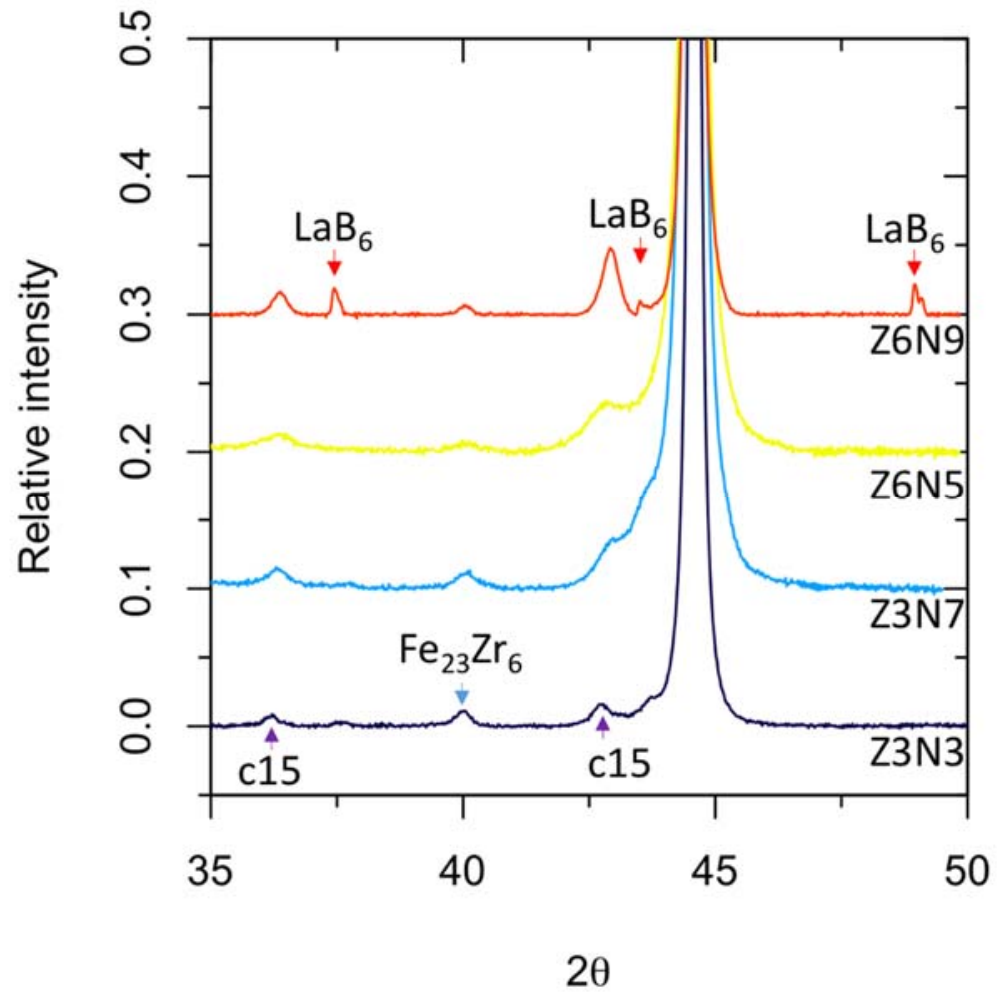

Figure 12. XRD patterns of the samples annealed at $1000{ }^{\circ} \mathrm{C}$ for 336 hours. 
In the earlier study of Fe-Cr-Zr ternary systems, $\mathrm{Cr}$ was found to enhance the formation of hexagonal Laves phase (C14 or C36) against the cubic Laves phase (C15) [15]. As a result, in a Fe-12.5Cr-10Zr system, peaks of C14/C36 were observed in XRD patterns instead of C15. However as shown in Figure 11 and 12 in this study, the Laves phase formed in the Fe-Cr-Zr-Ni systems favors C15 structure. In addition, based on the EDS analysis reported in Figure 6-9, there is considerable amount of Ni mixed in the C15 Laves phase. Given that $\mathrm{Ni}$ has smaller atomic radius than Fe does, the (Fe,Ni) ${ }_{2} \mathrm{Zr} \mathrm{C} 15$ structure has lattice parameter smaller than that of the $\mathrm{C} 15 \mathrm{Fe}_{2} \mathrm{Zr}$ Laves phase [16]. The mixture of $\mathrm{Ni}$ into the Laves phase is believed to stabilize the $\mathrm{C} 15$ structure over a temperature up to $1000{ }^{\circ} \mathrm{C}$, as shown in the experimental results in this study.

Similar to the $\mathrm{C} 15$ Laves phase, $\mathrm{Fe}_{23} \mathrm{Zr}_{6}$ was observed in the temperature range of $700-1000{ }^{\circ} \mathrm{C}$. Ni was also found to be the solute, forming $(\mathrm{Fe}, \mathrm{Ni})_{23} \mathrm{Zr}_{6}$. In $\mathrm{Fe}-\mathrm{Zr}$ binary system, $\mathrm{Fe}_{23} \mathrm{Zr}_{6}$ has been found to contain up to $1 \mathrm{w} . \% \mathrm{O}$ and thus considered as an oxygen-stabilized phase [17]. In Fe-Cr-Zr ternary system, the thermodynamic modeling showed that only a very small amount of energy $(0.68 \mathrm{KJ} / \mathrm{mole}$ atoms $)$ change is in need for $\mathrm{Fe}_{23} \mathrm{Zr}_{6}$ to become s stable phase [15]. In the Fe-Cr-Zr-Ni quaternary system, XRD investigations show considerable amount of $\left(\mathrm{Fe}, \mathrm{Ni}_{23} \mathrm{Zr}_{6}\right.$ observed in all experimental conditions in this study. Given the observations in this study, as well as previous considerations in the binary and ternary systems, it is very possible that $(\mathrm{Fe}, \mathrm{Ni})_{23} \mathrm{Zr}_{6}$ is a stable phase in the $\mathrm{Fe}-\mathrm{Cr}-\mathrm{Zr}-\mathrm{Ni}$ system. The addition of $\mathrm{Ni}$ to the $\mathrm{Fe}_{23} \mathrm{Zr}_{6}$ could stabilize it by providing multiple possible sites for the transition-metal elements with different atomic environments and associated volumes [18].

\subsection{TEM characterizations}

Figure 13 shows the results from TEM investigation of the Z3N7 sample after annealed at $700{ }^{\circ} \mathrm{C}$ for 1275 hours. As shown in Figure 13a, grains of $0.5 \mu \mathrm{m}$ in size were observed in the eutectic microstructures. Analysis of SAD patterns revealed that these grains with similar sizes have different crystal structures. The domain $\mathrm{C}$ was found to be the matrix phase, having a BCC crystal structure. The crystal structures of domains $\mathrm{B}$ and $\mathrm{E}$ are the $\mathrm{C} 15$ Laves structure and the $\mathrm{Fe}_{23} \mathrm{Zr}_{6}$ structure, respectively. The observations of these two crystal structures show agreement to the XRD results. Domain D was found to have a $\mathrm{Ni}_{7} \mathrm{Zr}_{2} \mathrm{C} 12$ structure, which was not marked in the XRD patterns in Figures 11-12 because of the overlapping of the strongest peak of the $\mathrm{Ni}_{7} \mathrm{Zr}_{2}$ with the (110) peak of BCC.
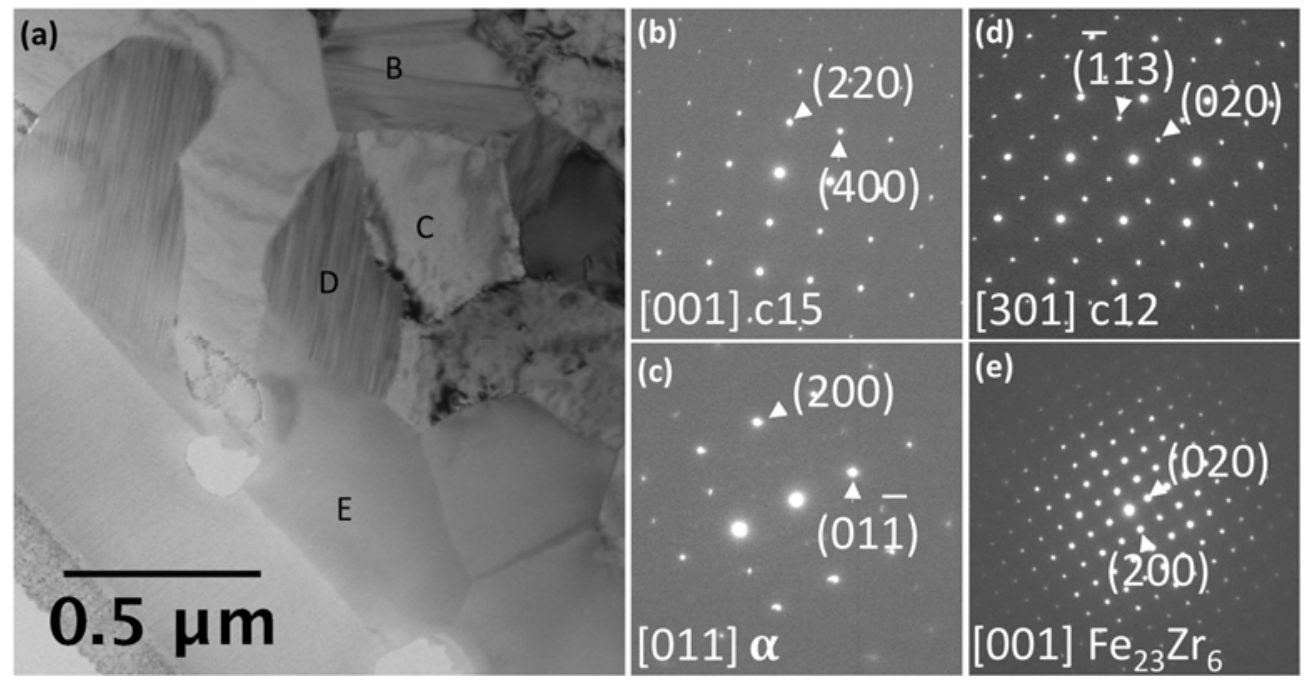

Figure 13. (a) A TEM bright-field image of the Z3N7 sample annealed at $700{ }^{\circ} \mathrm{C}$ for 1275 hours. (be) SAD patterns of the grains labeled as B-E in (a), respectively. 
The chemical compositions of each labeled domains in Figure 13a were determined using EDS technique. The averaged atomic percentages of $\mathrm{Fe}, \mathrm{Cr}, \mathrm{Ni}$ and $\mathrm{Zr}$ for each domain were listed in Table 3. Qualitatively, the chemical composition determined using TEM is in agreement with the estimation using SEM, which is shown in Figure 11. Given that the beam spot is much smaller in TEM, the EDS analysis from TEM is considered to be more accurate. With this accuracy, the compositions of the all three intermetallic phases found in current study are distinctive. The solublity of each intermetallic phase can be estimated. The $\mathrm{Ni}_{7} \mathrm{Zr}_{2}$ phase was found to be the Ni-rich phase as shown in the EDS mappings in Figure 69. Based on the compositions shown in Table 3, the formula of this phase is $\left(\mathrm{Ni}_{0.5} \mathrm{Fe}_{0.5}\right)_{7} \mathrm{Zr}_{2}$. The formulas of the $\mathrm{Fe}_{2} \mathrm{Zr}$ and $\mathrm{Fe}_{23} \mathrm{Zr}_{6}$ phases, as determined in the same manner, are $\left(\mathrm{Fe}_{0.7} \mathrm{Ni}_{0.3}\right)_{2} \mathrm{Zr}$ and $\left(\mathrm{Fe}_{0.8} \mathrm{Ni}_{0.2}\right)_{23} \mathrm{Zr}_{6}$, respectively.

Table 3. Chemical compositions of different phases in the Z3N7 sample annealed at $700{ }^{\circ} \mathrm{C}$ for 1275 hours.

\begin{tabular}{|l|l|l|l|l|}
\hline & Fe (at.\%) & Cr (at.\%) & Ni (at.\%) & Zr (at.\%) \\
\hline BCC phase & $84.59 \pm 0.16$ & $13.79 \pm 0.37$ & $1.49 \pm 0.09$ & $0.12 \pm 0.25$ \\
\hline $\mathrm{Fe}_{2} \mathrm{Zr}$ C15 & $49.82 \pm 2.36$ & $1.49 \pm 0.18$ & $17.49 \pm 0.31$ & $31.20 \pm 2.84$ \\
\hline $\mathrm{Fe}_{23} \mathrm{Zr}_{6}$ & $62.67 \pm 0.33$ & $4.01 \pm 0.10$ & $12.96 \pm 0.55$ & $20.37 \pm 0.78$ \\
\hline $\mathrm{Ni}_{7} \mathrm{Zr}_{2} \mathrm{C} 12$ & $37.43 \pm 2.00$ & $0.91 \pm 0.24$ & $37.05 \pm 0.35$ & $24.63 \pm 1.89$ \\
\hline
\end{tabular}

\section{CONCLUSIONS AND FUTURE WORK}

With the aid of computational thermodynamics, Ni was identified to suppress the liquidus temperature of $\mathrm{Fe}_{2} \mathrm{Zr}$ and four $\mathrm{Fe}-\mathrm{Cr}-\mathrm{Ni}-\mathrm{Zr}$ alloys were designed to study the Ni effect on the phase stability of $\mathrm{Fe}_{2} \mathrm{Zr}$ laves_phase. These alloys were fabricated through traditional arc-metling, followed by annealing at $1000^{\circ} \mathrm{C}$ for 336 hours and $700^{\circ} \mathrm{C}$ for 1275 hours. The microstructure were examined and characterized by SEM BSE image, EDS compositional mapping and point scan, XRD and TEM analysis. The major results were summarized below:

5) For investigated alloys with $12 \mathrm{wt} \% \mathrm{Cr}, 3 \sim 6 \mathrm{wt} \% \mathrm{Zr}$ and $3 \sim 9 \mathrm{wt} \% \mathrm{Ni}$, the phases in equilibrium with the BCC phase are C15_Laves phase, $\mathrm{Fe}_{23} \mathrm{Zr}$ phase. The volume fraction of intermetallic phases increases with $\mathrm{Ni}$ and $\mathrm{Zr}$ contents.

6) Instead of (Fe,Cr) ${ }_{2} \mathrm{Zr}$ C14_Laves phase, Ni stabilizes the C15_Laves structure in Fe-Cr-Ni-Zr alloys by substituting $\mathrm{Fe}$ and $\mathrm{Cr}$ atoms with $\mathrm{Ni}$ atoms in the first sublattice.

7) $\mathrm{Fe}_{23} \mathrm{Zr}_{6}$, that is metastable in the Fe-Cr-Zr ternary, is also stabilized by Ni addition.

8) $\mathrm{Ni}_{7} \mathrm{Zr}_{2}$ phase was observed in samples with high $\mathrm{Ni} / \mathrm{Zr}$ ratio.

The microstructural and composition results obtained from this study will be incorportated into the the Fe-Cr-Ni-Zr database. The current samples will be subjected to ion irradiaition to be compared with those results for $\mathrm{Fe}-\mathrm{Cr}-\mathrm{Zr}$ alloys. Additional alloys will be designed to form (Fe, $\mathrm{Cr}, \mathrm{Ni})_{2} \mathrm{Zr}$ nanoprecipitates for further studies. 


\section{REFERENCES}

[1] Zinkle SJ, Snead LL. Annual Review of Materials Research 2014;44:241.

[2] Raj B, Vijayalakshmi M. RJM Konings, TR Allen, RE Stoller, S. Yamanaka, Comprehensive Nuclear Materials, Elsevier 2012.

[3] Tan L, Yang Y. Metallurgical and Materials Transactions A 2015;46:1188.

[4] Hellstern E, Schultz L. Materials Science and Engineering 1988;97:39.

[5] Castaño F, Stobiecki T, Gibbs M, Czapkiewicz M, Kopcewicz M, Gacem V, Speakman J, Cowlam N, Blythe H. Journal of Physics: Condensed Matter 1997;9:10603.

[6] Byeli A, Kukareko V, Kononov A, Bilenko E. Journal of Surface Investigation. X-ray, Synchrotron and Neutron Techniques 2008;2:340.

[7] Yu K, Fan Z, Chen Y, Song M, Liu Y, Wang H, Kirk M, Li M, Zhang X. Materials Research Letters 2015;3:35.

[8] Tan L. Development and Mechanical Results of Zr-Bearing Ferritic Steels. Oak Ridge National Laboratory (ORNL), 2015.

[9] Lu Z, Liu C. Acta materialia 2002;50:3501.

[10] Takeuchi A, Inoue A. Materials Transactions 2005;46:2817.

[11] Johnson WL. Fundamental aspects of bulk metallic glass formation in multicomponent alloys. Materials science forum, vol. 225: Trans Tech Publ, 1996. p.35.

[12] Ma D, Cao H, Ding L, Chang YA, Hsieh K, Pan Y. Applied Physics Letters 2005;87:171914.

[13] Yan X-Y, Chang Y, Yang Y, Xie F-Y, Chen S-L, Zhang F, Daniel S, He M-H. Intermetallics 2001;9:535.

[14] Kaufman L, Bernstein H. 1970.

[15] Yang Y, Tan L, Bei H, Busby JT. Journal of Nuclear Materials 2013;441:190.

[16] Muraoka Y, Shiga M, Nakamura Y. physica status solidi (a) 1977;42:369.

[17] Stein F, Sauthoff G, Palm M. Journal of Phase Equilibria 2002;23:480.

[18] Ohodnicki Jr P, Cates N, Laughlin D, McHenry M, Widom M. Physical Review B 2008;78:144414. 